Research Article

\title{
Knowledge Framework and Evolution of Fuzzy Portfolio Research: A Bibliometric Analysis
}

\author{
Wei Zhou (iD, Qinen Gu (D), and Dongping Yu (iD \\ School of Finance, Yunnan University of Finance and Economics, Kunming 650221, China \\ Correspondence should be addressed to Dongping Yu; yudongping@ynufe.edu.cn
}

Received 1 February 2020; Revised 18 June 2020; Accepted 24 July 2020; Published 28 August 2020

Academic Editor: Caroline Mota

Copyright (c) 2020 Wei Zhou et al. This is an open access article distributed under the Creative Commons Attribution License, which permits unrestricted use, distribution, and reproduction in any medium, provided the original work is properly cited.

Recently, wide applications of fuzzy set theory have attracted the attention of both researchers and practitioners. Fuzzy portfolio develops as a new area in the research field of investment portfolio. This paper investigates the major research hotspots, development trend, and evolution of fuzzy portfolio, which provides a systematic review of the current fuzzy portfolio literature. CiteSpace, the most commonly used bibliometrics software, is used in this article. According to the 602 articles with 15132 references, several conclusions can be summarized as follows: (1) Fuzzy portfolio becomes increasingly interdisciplinary with the connections among "Computer Science" and so on. (2) Most contributive authors are Markowitz and Zadeh. (3) South China University of Technology makes excellent performance in this research area and China is the most influential country. (4) European Journal of Operations Research is the cradle of plenty of crucial fuzzy portfolio investigations. (5) We find some research hotspots helpful to make scientific predictions of future trends by analyzing the keywords. By utilizing the effective bibliometric methods, we provide a comprehensive analysis and deep insights into the fuzzy portfolio research, enabling the individuals, especially the new beginners who are interested in this area to learn fuzzy portfolio, which will be of great help for their future explorations.

\section{Introduction}

In the financial market, investment portfolios are attracting investors' attention as an effective risk-distributing tool. Its core concept is to effectively allocate assets in an uncertain environment. Fuzzy portfolio refers to the application of fuzzy logic to the selection of portfolio and the construction of the model to achieve the goal of optimizing the investment portfolio. The relevant research has grown since the introduction of the fuzzy portfolio, and such articles that apply fuzzy logic variables, fuzzy logic functions, and likelihood reasoning to portfolio optimization and selection have laid a theoretical foundation for finding breakthroughs in solving ambiguities in investment. Due to the rapid growth and great practical significance of fuzzy portfolio research, it is crucial to analyze the research development of this area.

Previous theories show that the uncertainty of portfolio selection problems consists of random uncertainty and fuzzy uncertainty. Compared with random uncertainty, fuzzy uncertainty that describes state uncertainty of the event itself is a more profound uncertainty. That is the reason that there are a growing number of researchers focusing on applying fuzzy decision theory on portfolio research. In real life, an investment decision-making activity is affected by many human factors such as social, psychological, subjective will, and work experience. How to effectively consider the influence of human factors on investment decisions in the investment decision-making process has always been considered by the majority of scholars. Zadeh [1] proposed possibility theory which makes an outstanding contribution to the solution of the uncertainty of subject decision-making field in the portfolio. Östermark [2] used fuzzy decision theory to study the dynamic portfolio problem with a riskfree asset and multiple risk assets, and a fuzzy control model was proposed. Tanaka and Guo [3] identified two kinds of possibility distributions to reflect experts' knowledge in portfolio selection problems. These are some basic theories to select the optimal investment ratios. 
Moreover, many scholars further have used fuzzy theory to cope with the problem of portfolio decision. León et al. [4] used fuzzy decision methods to study the infeasible problems that may arise in the portfolio selection model. Carlsson et al. [5] regarded investment income as a trapezoidal fuzzy number and proposed a fuzzy probability portfolio model with maximum utility without allowing short selling. Fang et al. [6] used the fuzzy decision theory to study the portfolio rebalance model with transaction cost. Tiryaki and Ahlatcioglu [7] used AHP to sort a set of stocks in a fuzzy investment environment in order to demonstrate the practicality of fuzzy decision-making methods in financial decision-making problems. Zhang and Xiao [8] defined the weighted lower and upper possibilistic variances and covariances of fuzzy numbers. Subsequently, many scholars studied the fuzzy portfolio selection problems based on the numerical feature theory of fuzzy numbers. In the current field of fuzzy portfolio research, most scholars explored the choice of portfolios in practice by constructing mathematical models. Silva et al. [9] developed a new fuzzyDEA-Game (FOG) model to support the establishment of production strategies by combing Data Envelopment Analysis (DEA) with the concept of Fuzzy Set Theory and Nash Bargaining Game. Yue and Wang [10] proposed a new entropy function based on Minkowski and designed a new multiobjective evolutionary algorithm to overcome the low diversity of the obtained solution set. Chen et al. [11] proposed a possibilistic mean semiabsolute deviation portfolio model with $\mathrm{V}$-shape transaction costs to deal with portfolio adjusting problem. Liu et al. [12] and Liu and Zhang [13] discussed a multiperiod portfolio selection with discounted transaction costs in a fuzzy uncertain investment environment. Alali and Tolga [14] adapted TODIM to the portfolio allocation process and verified portfolio based on outperforming TODIM configurations yields significantly better results than equally weighted portfolio $(1 / N)$ and insignificantly inferior result than minimum variance portfolio in terms of the sharp ratio.

With the development of fuzzy portfolio research, it is necessary to know its emerging trend. Bibliometrics can help researchers sort through the development track of knowledge. Bibliometrics refers to the quantitative analysis of the cross-science of all knowledge carriers using mathematical and statistical methods. It is a comprehensive knowledge system including mathematics, statistics, and philology. Nowadays, many scholars are committed to applying bibliometrics to the study of finance. Based on Java language, CiteSpace was proposed by Chen [15], which is a widely used tool in bibliometrics. Rang and Zeng [16] made a visual analysis of the Chinese finance studies in recent ten years using CiteSpace. Costa et al. [17] conducted a bibliometric analysis on the association between the themes "behavioral finance" and "financial and managerial decision making," and the cognitive biases "overconfidence," "anchoring effect," and "confirmation bias." Xu et al. [18] investigated the development trend of research on supply chain finance adopting a systematic literature review methodology combined with bibliometric. These papers make a great contribution to the development of the finance field.
Despite a wide range of publications related to fuzzy portfolio, few investigations focus on the vital trend and potential relationships of papers. By using CiteSpace, this paper analyzes the important node articles in the field of fuzzy portfolio research in the past 20 years. The analyses such as the current status of the fuzzy portfolio research, the distribution of countries and institutions, the distribution of authors, the co-occurrence of keywords, the cocitation of the references, and the cocitation of journals are provided. The research hotspots and research frontiers of the fuzzy portfolio are revealed to develop new ideas for improving the research system in this field. This paper is organized as follows: Section 2 introduces how to use CiteSpace and how to collect the data. Section 3 conducts the analysis of cocitation, co-occurrence, and cooperation network. Conclusions and future expectations are illustrated in Section 4.

\section{Methodology and Data Collection}

For an article, the collection of data and the choice of research approaches are crucial. In this section, we first introduce the effective bibliometric tool CiteSpace and introduce the selection of the database and the collection of data, including the setting of various parameters, which can ensure the accuracy of the research.

2.1. Research Method. Database plays an important role in the field of science research. In order to improve the accuracy and convenience of information acquisition, many scholars and organizations have developed bibliometric software to explore the intrinsic links among literature. As a broadly used bibliometric software, CiteSpace was developed by Professor Chen [15] which is a commonly used software for bibliometric based on Java to present knowledge structure and research dynamics. Compared with other bibliometric software, CiteSpace is more suitable for dynamic analysis in research areas. The characteristic of CiteSpace is visualizing results by "Cluster," "Timeline," and "Time zone." The reason CiteSpace can become the most commonly used bibliometric software is to combine traditional bibliometrics and popular information visualization to explore the intrinsic or extrinsic relationship among different topics. Hidden potential relationships can be intuitively observed from the scientific distribution map of articles, which can lay a good foundation for scientific research.

Figure 1 shows the architecture diagram of the process about the data collection and the use of CiteSpace, which presents the selection of specific parameters during the use of CiteSpace. In the process of collecting data, the topic is "fuzzy portfolio" and the time span is "all years." The database is from Science Citation Index Expanded (SCI-E) and Social Science Citation Index (SSCI). There are 2 steps when we use CiteSpace to get the statistic results. First of all, we build a program. It mainly includes three subdivision steps of importing data, setting project, and naming program. Next, we set the parameter. Based on the 602 document data, the node types of the CiteSpace interface are set as "author," "cited author," "Country," "Institution," "Keyword," "Reference," and "Cited Journal." Knowledge maps of the 


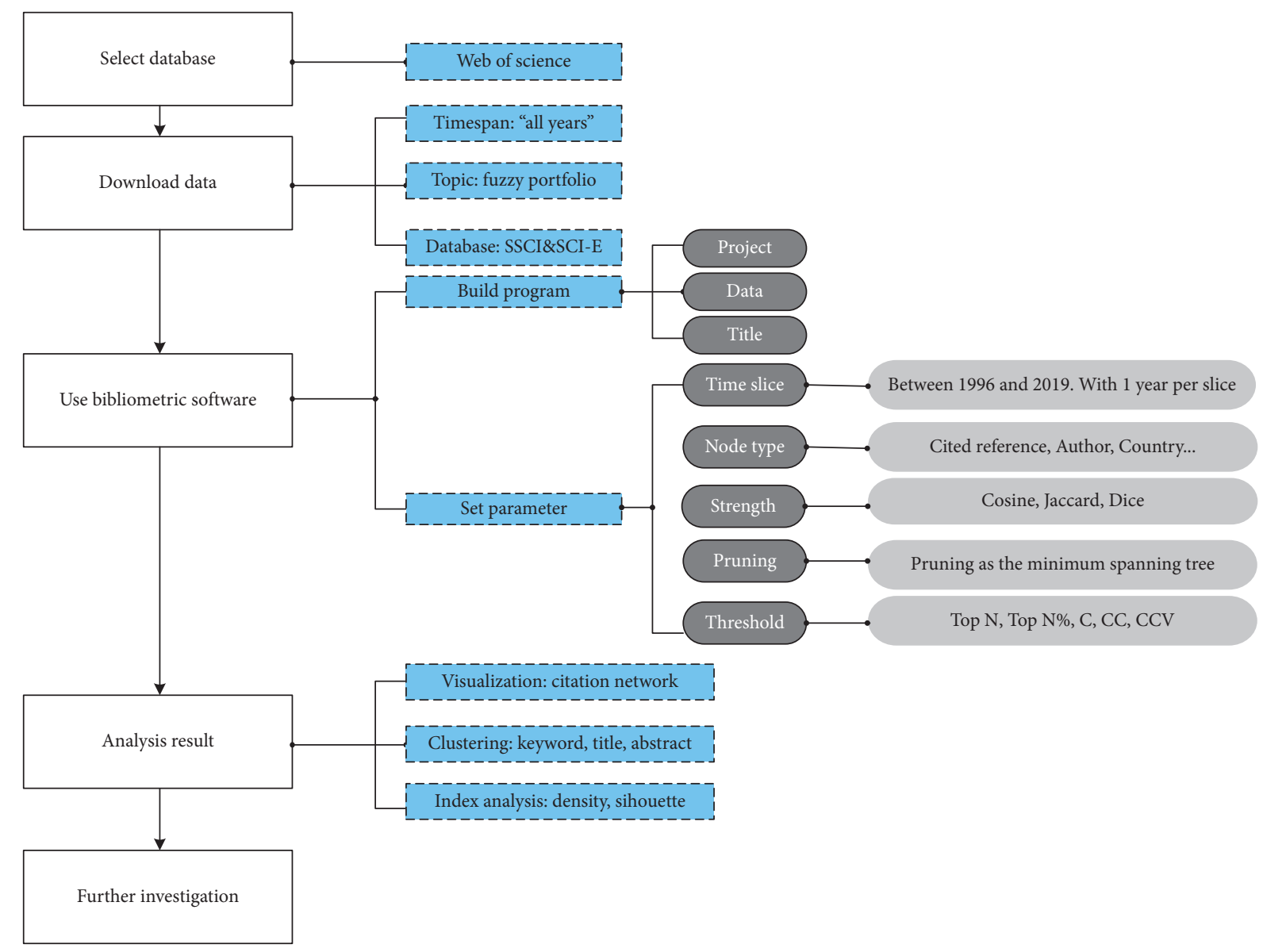

FIgURE 1: Architecture diagram of the use of CiteSpace.

research on fuzzy portfolio are represented intuitively. In the time zone split setting, this paper chose a time span of 1996-2020, meaning that the landscape view is generated based on publications between 1996 and 2020. Time slice defines the time interval and range length of the selected literature, in this part. The time slice is 1 year apart, and the data selection criteria are the top 100 most cited articles in each time period. It means the top 100 most cited publications in each year are used to construct a network of references cited in that year [15]. Threshold is the criteria for selecting items during modeling and visualization and threshold selection is the default. Pruning exists in order to reduce the waiting time, and the concurrent version of the algorithm is used to process multiple networks at the same time. Keyword analysis gives information about research hotspots and research frontiers. Cocitation analysis of the literature can report the relevance of each document among the keywords. Journal cocitation analysis can find the core journals of research results. Besides, influential authors can be known based on cited author analysis.

2.2. Data Collection. To ensure the research significance of the article, it is crucial to select high-quality journal articles as reliable sources of knowledge. In terms of the field of fuzzy portfolio research, the articles related to fuzzy portfolio research are searched from Web of Science (WoS). WoS established by Institution of Science Information is the largest and the most comprehensive academic resource in the world, which covers more than 8,700 core academic journals in the most influential fields of natural sciences, engineering, and biomedical sciences, and so on. As a credible and comprehensive bibliographic database, WoS is the most commonly used database in the research of bibliographic. Choosing WoS as the source of knowledge can widely acquire high-quality journal articles. In this paper, data are retrieved based on WoS core journals. Data were searched on May 29, 2020. The time span is all years. The topic word is "fuzzy portfolio," and the search has a total of 696 articles. In order to ensure the high correlation between the selected data and the topic "fuzzy portfolio" and improve the accuracy of the result, we have refined the data manually by removing 94 unrelated data. Finally, there are 602 valid references being analyzed in the revised manuscript. By updating the version, the results of this paper could be more representative and coherent.

\section{Current Status of the Fuzzy Portfolio Research}

The number of publications and citations in recent years fully explains the increasing concerns of fuzzy portfolio research. A full set of records for 602 publications were 
retrieved and downloaded on May 29, 2020. The number of publications and citations per year in the fuzzy portfolio research for each year is indicated in Figure 2. Columns represent the number of publications per year and the line describes the trend of the citation. This figure witnesses a remarkable increase over almost 20 years. The number of publications has reached a plateau at approximately 50 publications per year in recent years. The number of citations per year is on the rise until 2020. It can be seen that the research on fuzzy portfolio has made great progress in the recent 20 years. According to the growth curve of fuzzy portfolio research, three stages can be identified as follows:

(1) Start-up phase (2000-2004): at this stage, the number of documents published each year is less than 10 and the growth is slow. The research on fuzzy portfolio starts to attract a few attentions of scholars. There are also influential authors during this period such as Inuiguchi, Tanaka, and Parra. Inuiguchi and Ramík [19] described the fuzzy linear programming and techniques. Tanaka et al. [20] proposed two kinds of portfolio selection models based on fuzzy probabilities and possibility, which are entirely different from probability distribution in Markowitz's model. Parra et al. [21] used a fuzzy genetic algorithm to solve multiobjective programming problems of income, risk, and liquidity in investment. The authors' researches laid a solid foundation for the research of fuzzy portfolio and made outstanding contributions to the development of research.

(2) Initial development phase (2005-2012): at this stage, research on this aspect is gradually increasing and growing rapidly. The annual number of published papers increased from 16 in 2005 to 47 in 2011. The number has increased dramatically since 2008, which means the occurrence of the subprime mortgage crisis may increase the attention of scholars in the research of fuzzy portfolio. During this period, Wang, Amiri, and Li are the most influential authors. Wang and Hwang [22] developed a fuzzy R\&D portfolio selection model to hedge against R\&D uncertainty. Amiri [23] used six criteria for comparing investment alternatives as criteria in an AHP and fuzzy TOPSIS techniques to analyze the structure of the project selection problem. Li et al. [24] proposed a mean-variance-skewness model and considered the corresponding variations.

(3) Rapid development phase (2013-2020): at this stage, the number of published papers has arrived at a platform about 50 per year and continues to grow. The subprime mortgage crisis that broke out in 2008 has increased the awareness of financial risk management among investors, regulatory authorities, and scholars. Fuzzy portfolios can effectively hedge risk through reasonable asset ratios. Zhang and Gupta are the most contributive authors from 2012 to 2019. Zhang et al. [25] solved a multiperiod portfolio selection problem with fuzzy returns.
Gupta et al. [26] proposed a multiobjective credibility model with fuzzy chance constraints of the portfolio selection problem.

All the documents of fuzzy portfolio research are composed of 4 different file types, such as article, proceeding paper, review, and correction. Figure 3 reveals the details of each type.

Each of the journals and books included in the WoS core collection belongs to at least one subject category. Therefore, each record in the core collection of WoS has a "WoS category" field that contains the subject category to which its source publication belongs. According to categories distribution, it can be clearly concluded that fuzzy portfolio research has become multidisciplinary. Summary of the top 10 categories in the fuzzy portfolio research area is listed in Table 1. Obviously, "Computer Science Artificial Intelligence" is the most popular category with 248 publications, accounting for $35.378 \%$ of the total publications, which means that the idea of fuzzy portfolios is widely used in the field of computer science and artificial intelligence. "Operations Research Management Science" is the second most popular category after "Computer Science Artificial Intelligence," with 162 publications, accounting for $23.11 \%$ of the total publications. Fuzzy logic is a concept of the operational research that is the main reason for this phenomenon. The remaining eight subject categories are as follows: "Engineering Electrical Electronic" (91), "Computer Science Interdisciplinary Applications” (89), "Management” (88), "Mathematics Applied" (67), "Computer Science Information Systems" (57), "Computer Science Theory Methods" (50), "Economics" (49), and "Mathematics Interdisciplinary Applications" (42). By analyzing categories, we find that fuzzy portfolio is widely used in various research fields.

The top 10 research directions in the fuzzy portfolio research are listed in Table 2. According to this table, "Computer Science" is the foremost research direction at present, accounting for 51.159\%. "Engineering" is the second important research direction after "Computer Science," with 174 publications, accounting for 26.893\%, followed by "Operations Research Management Science," with 155 publications, accounting for $23.957 \%$. In addition, other research directions with the percentage of total more than $10 \%$ are "Business Economics" and "Mathematics," while research directions such as "Automation Control Systems," "Science Technology Other Topics," "Energy Fuels," and "Environmental Sciences Ecology" have smaller proportions.

The article can more intuitively reflect the research direction of fuzzy portfolio research. Table 3 sets out the top 20 most used documents of WoS in fuzzy portfolio research. These articles have been published between 1994 and 2012, and articles are from different kinds of journals. Among them, 7 articles are from European Journal of Operational Research. The publications mentioned in Table 3 relate to subjects including operational research, management science, and economic, which is the same as the phenomenon indicated in Tables 1 and 2. 


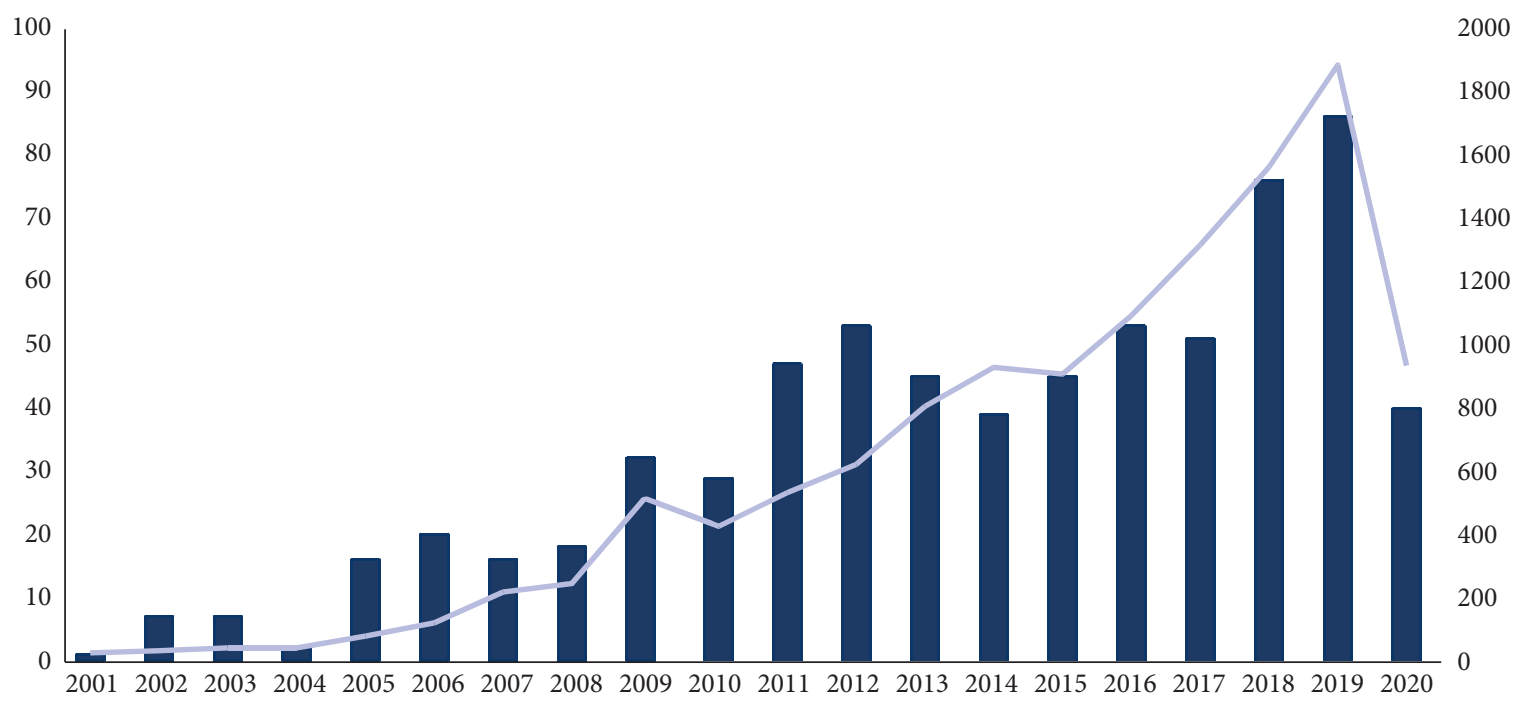

FIGURE 2: Number of publications and citations per year in the fuzzy portfolio research.

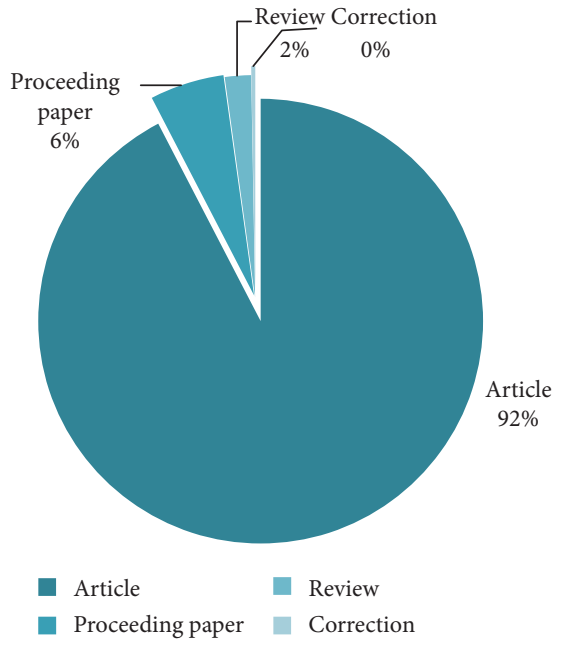

FIgURE 3: The document types in the fuzzy portfolio research.

TABLE 1: The top 10 subject categories of WoS in the fuzzy portfolio research.

\begin{tabular}{lcc}
\hline Subject categories of WoS & Number & The percentage of total \\
\hline Computer Science Artificial Intelligence & 248 & 35.378 \\
Operations Research Management Science & 162 & 23.110 \\
Engineering Electrical Electronic & 91 & 12.981 \\
Computer Science Interdisciplinary Applications & 89 & 12.696 \\
Management & 88 & 12.553 \\
Mathematics Applied & 67 & 9.558 \\
Computer Science Information Systems & 57 & 8.131 \\
Computer Science Theory Methods & 50 & 7.133 \\
Economics & 49 & 6.990 \\
Mathematics Interdisciplinary Applications & 42 & 6.491 \\
\hline
\end{tabular}


TABLE 2: The top 10 research directions of WoS in the fuzzy portfolio research.

\begin{tabular}{lcc}
\hline Research directions of WoS & Number & The percentage of total \\
\hline Computer Science & 331 & 51.159 \\
Engineering & 174 & 26.893 \\
Operations Research Management Science & 155 & 23.957 \\
Business Economics & 130 & 20.093 \\
Mathematics & 114 & 17.620 \\
Automation Control Systems & 30 & 4.637 \\
Science Technology Other Topics & 30 & 4.637 \\
Energy Fuels & 20 & 3.091 \\
Environmental Sciences Ecology & 15 & 2.318 \\
Physics & 10 & 1.546 \\
\hline
\end{tabular}

TABLE 3: The top 20 most used articles of WoS in the fuzzy portfolio research.

\begin{tabular}{|c|c|c|c|c|}
\hline Title & Authors & Number & Source & Year \\
\hline $\begin{array}{l}\text { Possibilistic linear programming: a brief review of fuzzy } \\
\text { mathematical programming and a comparison with stochastic } \\
\text { programming in portfolio selection problem [19] }\end{array}$ & $\begin{array}{l}\text { Inuiguchi and } \\
\text { Ramík }\end{array}$ & 432 & Fuzzy Sets and Systems & 2000 \\
\hline Perspective-3rd-generation new product processes [27] & Cooper & 358 & $\begin{array}{l}\text { Journal of Product Innovation } \\
\text { Management }\end{array}$ & 1994 \\
\hline Integrating the fuzzy front end of new product development [28] & $\begin{array}{l}\text { Khurana and } \\
\text { Rosenthal }\end{array}$ & 242 & Sloan Management Review & 1997 \\
\hline $\begin{array}{l}\text { Portfolio selection based on fuzzy probabilities and possibility } \\
\text { distributions [20] }\end{array}$ & Tanaka et al. & 203 & Fuzzy Sets and Systems & 2000 \\
\hline A fuzzy goal programming approach to portfolio selection [21] & Parra et al. & 177 & $\begin{array}{l}\text { European Journal of } \\
\text { Operational Research }\end{array}$ & 2001 \\
\hline $\begin{array}{l}\text { A fuzzy set approach for } R \& D \text { portfolio selection using a real } \\
\text { options valuation model [22] }\end{array}$ & Wang and Hwang & 162 & $\begin{array}{l}\text { Omega-International Journal of } \\
\text { Management Science }\end{array}$ & 2007 \\
\hline $\begin{array}{l}\text { Portfolio selection based on upper and lower exponential } \\
\text { possibility distributions [3] }\end{array}$ & Tanaka and Guo & 150 & $\begin{array}{l}\text { European Journal of } \\
\text { Operational Research }\end{array}$ & 1999 \\
\hline $\begin{array}{l}\text { A novel two-phase group decision making approach for } \\
\text { construction project selection in a fuzzy environment [29] }\end{array}$ & Ebrahimnejad et al. & 149 & $\begin{array}{l}\text { Applied Mathematical } \\
\text { Modelling }\end{array}$ & 2012 \\
\hline $\begin{array}{l}\text { Mean-variance-skewness model for portfolio selection with fuzzy } \\
\text { returns [24] }\end{array}$ & Li et al. & 148 & $\begin{array}{l}\text { European Journal of } \\
\text { Operational Research }\end{array}$ & 2010 \\
\hline $\begin{array}{l}\text { A comparative survey of artificial intelligence applications in } \\
\text { finance: artificial neural networks, expert system and hybrid } \\
\text { intelligent systems [30] }\end{array}$ & Bahrammirzaee & 140 & $\begin{array}{l}\text { Neural Computing \& } \\
\text { Applications }\end{array}$ & 2010 \\
\hline A fuzzy approach to R\&D project portfolio selection [31] & Carlsson et al. & 131 & $\begin{array}{l}\text { International Journal of } \\
\text { Approximate Reasoning }\end{array}$ & 2007 \\
\hline Mean-semivariance models for fuzzy portfolio selection [32] & Huang & 121 & $\begin{array}{l}\text { Journal of Computational and } \\
\text { Applied Mathematics }\end{array}$ & 2008 \\
\hline Fuzzy portfolio optimization under downside risk measures [33] & Vercher et al. & 118 & Fuzzy Sets and Systems & 2007 \\
\hline $\begin{array}{l}\text { Genetic algorithms for portfolio selection problems with } \\
\text { minimum transaction lots [34] }\end{array}$ & Lin and Liu & 117 & $\begin{array}{l}\text { European Journal of } \\
\text { Operational Research }\end{array}$ & 2008 \\
\hline $\begin{array}{l}\text { Asset portfolio optimization using fuzzy mathematical } \\
\text { programming [26] }\end{array}$ & Gupta et al. & 104 & Information Sciences & 2008 \\
\hline $\begin{array}{l}\text { Product portfolio identification based on association rule mining } \\
\text { [35] }\end{array}$ & Jiao and Zhang & 103 & Computer-Aided Design & 2005 \\
\hline $\begin{array}{l}\text { Portfolio rebalancing model with transaction costs based on fuzzy } \\
\text { decision theory [6] }\end{array}$ & Fang et al. & 100 & $\begin{array}{l}\text { European Journal of } \\
\text { Operational Research }\end{array}$ & 2006 \\
\hline Fuzzy chance-constrained portfolio selection [36] & Huang & 93 & $\begin{array}{l}\text { Applied Mathematics \& } \\
\text { computation }\end{array}$ & 2006 \\
\hline The valuation of European options in uncertain environment [37] & Yoshida & 88 & $\begin{array}{l}\text { European Journal of } \\
\text { Operational Research }\end{array}$ & 2003 \\
\hline $\begin{array}{l}\text { Viability of infeasible portfolio selection problems: a fuzzy } \\
\text { approach [4] }\end{array}$ & Leon et al. & 88 & $\begin{array}{l}\text { European Journal of } \\
\text { Operational Research }\end{array}$ & 2002 \\
\hline
\end{tabular}




\section{Mapping and Analysis on Authors, Institutions, and Countries}

4.1. Author and Cited Author Analysis. In this part, we make the analysis on authors and cited author. In the research of authors, we focus on the number of publications of each author and the close cooperation between authors, which can help us find the author who has the most articles. On the research of cited author, CiteSpace shows us authors with high citation, which can help us to find the most important authors in the research field of fuzzy portfolio. The analysis on author and cited author can help us not only find the most influential authors but also identify the development track.

Figure 4 shows a visualization of the author collaboration network. There are 491 nodes and 403 links in this figure. Each node represents the number of articles published by one author, and the links represent cooperation between authors. The overall density of the network is only 0.0034, which indicates that this network diagram is not compact enough. It can be concluded from Figure 4 that, in the field of fuzzy portfolio research, the research directions of the authors are relatively scattered for the reason that graphs presented are relatively discrete. Although there are overlaps, there are few connections and cooperation among them. Zhang has the largest number of publications and closely related to him, Liu is from South China University of Technology. Huang is from University of Science and Technology Beijing. Combining with the analysis on institution, we can draw a conclusion that authors with close cooperation belong to one institution.

Table 4 makes a list of the top 10 most productive authors. The author who has the most articles is Zhang, who mainly focuses on the research of fuzzy portfolio selection and optimization. Zhang et al. [38] regarded the return on assets as a fuzzy number under the theory of the numerical characteristics of fuzzy numbers. And this is followed by Mehlawat who is dedicated to the research of asset allocation. Huang [39] gave a new definition of portfolio risk in a fuzzy environment and proposed a meanrisk curve model based on this definition. It should be noted that even though they are significant contributors in fuzzy portfolio research field, the productive authors are not the ones who have been cited most frequently.

The analysis of citied authors can help us not only find the most influential researchers but also identify the development track of core authors in different periods. The top 10 most cited authors are listed in Table 5. The map of the cited author network is also depicted in Figure 5. These authors are leading the development of fuzzy portfolio research. It can be summarized from Table 5 and Figure 5 that Zadeh and Markowitz are the two authors identified as the most significant founders in this field. Zadeh [40] proposed fuzzy logic and hold the point that there are no precise boundaries between object classes in reality. The introduction of fuzzy logic has made an outstanding contribution to the development of operations research. Markowitz [41] proposed a mean-variance theory, which opened the curtain of modern finance research. The basic idea of the MV model is to measure the "return" by the expected return of the asset, the variance of the return on the asset as the risk measure, and the pursuit of the maximization of the expected return of the portfolio in the case of a certain risk or the situation in which the expected return of the portfolio is certain. The model quantitatively analyzes the risks and opens up new ideas for the study of risk management theory. Since then, finance has really entered the era of quantitative analysis. This is seen in the theoretical world as the first financial revolution that took place on Wall Street in the 20th century. Following the MV model, research on portfolio issues has attracted widespread attention from many scholars and has yielded rich research results. Since the securities market is a highly complex system, the securities return and risks are uncertain, leading investors make investment decisions in an uncertain environment.

Figure 6 shows the time zone view of the cited author. The time zone view of the cited author reflects the time when cited authors published an article and authors' influence distribution on the time axis. The position of the center of the circle corresponds to the horizontal axis representing the time when the author published the article. The size of the node represents the frequency their articles have been cited and the link represents reference between authors. As can be summarized from the time zone view of the cited author, the most influential author published papers for the period 1999-2008. The active authors at this stage are Zadeh, Markowitz, and Carlsson. Zadeh [40] is the creator of the fuzzy mathematics concept. Markowitz [41] is the initiator of the concept of the mean-variance model. By comparing the distribution map of cited authors with the publication map of authors, we find that the author with more articles may not be cited frequently. Only Huang and Zhang appear in the list of the top 10 cited authors in the number of published articles. It is an evidence that in the past decade, the academic achievements of Huang and Zhang have been widely recognized.

4.2. Institution and Country Analysis. The distribution characteristics of countries and institutions can reveal the contribution of the various regions of the world in the fuzzy portfolio, the influence, and the mutual cooperation between them. We can analyze the reasons for their outstanding achievements in the research field of fuzzy portfolio from the most influential countries and institutions.

The number of articles published by institutions is shown in Figure 7. This figure contains 79 nodes and 39 links, and the overall density is 0.013 . Each node represents an institution, and links indicate the cooperation between research institutions. In addition, colors are used to measure time. The closer to purple, the farther it is from now. The closer to yellow, the closer it is from now. We can find node color is mainly yellow, which illustrates most of the documents produced by these institutions were come out in recent years. The links between the various institutions are not complex, and the color is mainly yellow, indicating that there are fewer relationships but carried out in recent years. By observing Figure 7, it is easy to find the most influential research groups of fuzzy portfolio world 


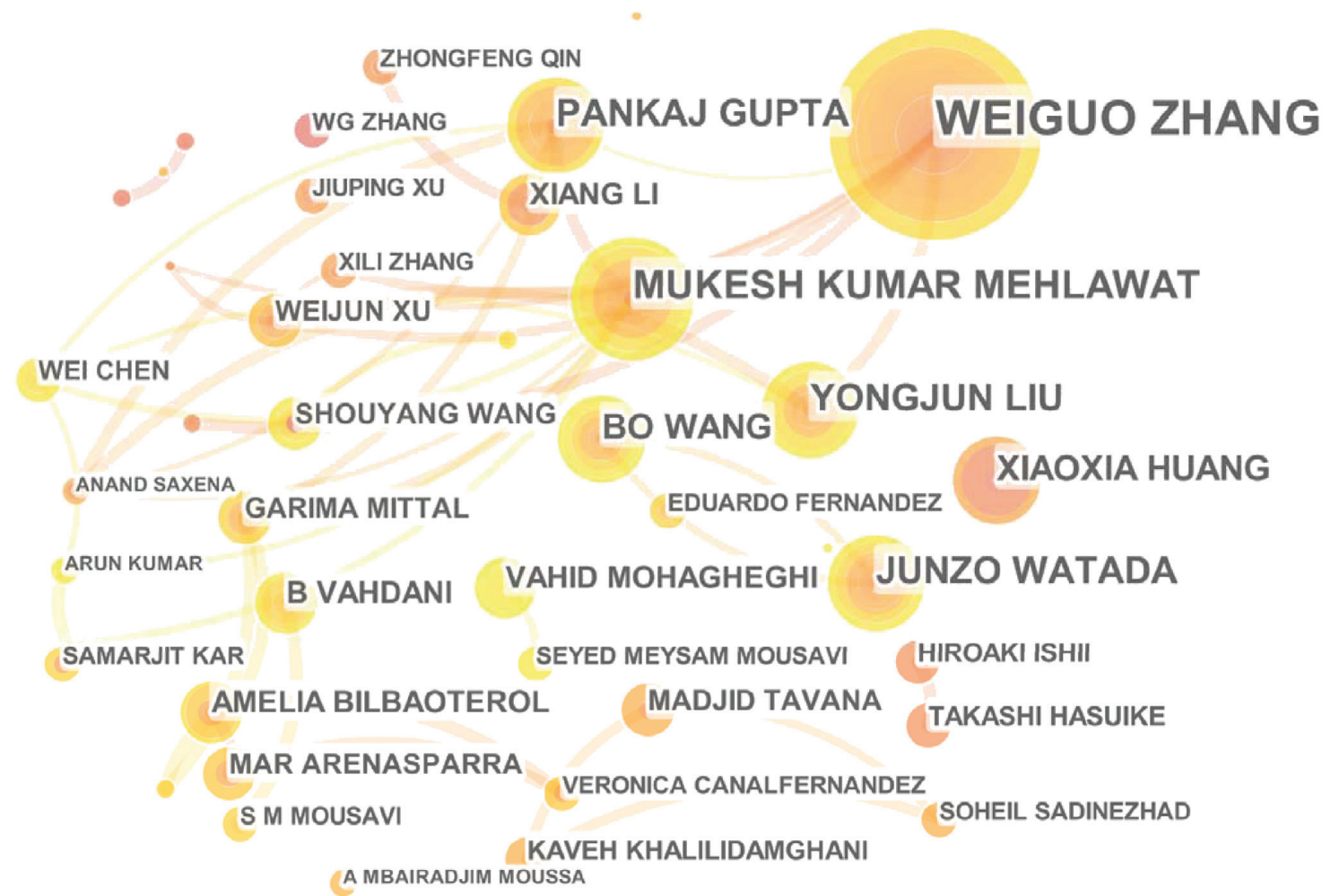

FIgURE 4: A visualization of the author collaboration network.

TABLE 4: top 10 most productive authors.

\begin{tabular}{lcc}
\hline Author & Number of publications & Year \\
\hline Zhang & 24 & 2007 \\
Mehlawat & 14 & 2008 \\
Watada & 11 & 2011 \\
Gupta & 11 & 2008 \\
Liu & 11 & 2012 \\
Wang & 10 & 2011 \\
Huang & 7 & 2009 \\
Bilbao-Terol & 10 & 2009 \\
Mohagheghi & 7 & 2019 \\
Li & 7 & 2009 \\
\hline
\end{tabular}

TABle 5: The top 10 most cited authors.

\begin{tabular}{lcc}
\hline Author & Frequency & Centrality \\
\hline Markowitz & 370 & 0.03 \\
Zadeh & 314 & 0.02 \\
Huang & 226 & 0.03 \\
Carlsson & 159 & 0.11 \\
Dubois & 142 & 0.08 \\
Zhang & 133 & 0.06 \\
Tanaka & 128 & 0.08 \\
Li & 118 & 0.10 \\
Liu & 109 & 0.04 \\
Liu & 102 & 0.04 \\
\hline
\end{tabular}

widely through institution analysis. It is obvious that China is the leading country in the research of fuzzy portfolio. There are 9 Chinese institutions in the 20 most productive institutions, which corresponds with the conclusion that China is the most productive country. Among the 20 mentioned institutions in Table 6, nine are from China. Iran has four. Spain and Japan have two, respectively. India, America, and France each have one. South China University of Technology ranks first, with 38 publications. South China University of Technology and other institutions have extensive cooperation, including Xi'an Jiaotong University and Sun Yat-sen University. Occupying the second position is the Islamic Azad University, with 23 publications. Other institutions with publications over 10 include Shahed University (17), University of Delhi (16), University of Science and Technology Beijing (14), Hebei University (14), Capital University of Economics and Business (12), Waseda University (12), Chinese Academy of Sciences (12), University of Oviedo (12), Beijing University of Chemical and Technology (12), Sichuan University (11), University of Tehran (11), and Osaka University (11). Zhang is a professor of South China University of Technology, whose team makes outstanding contributions to the research field of fuzzy portfolio.

Centrality is an important indicator of the importance of a node in the network. In general, if a centrality of a node is greater than 0.01 , it can be considered as a certain influence of the node in the field. Combined with Table 6, the centrality of nodes representing Capital University of Economics and Business and Sichuan University is 0.02. Other institutions include South China University of Technology (0.01), University of Delhi (0.01), and Islamic Azad University (0.01), which means that these institutions have great influence and are worthy of attention. 


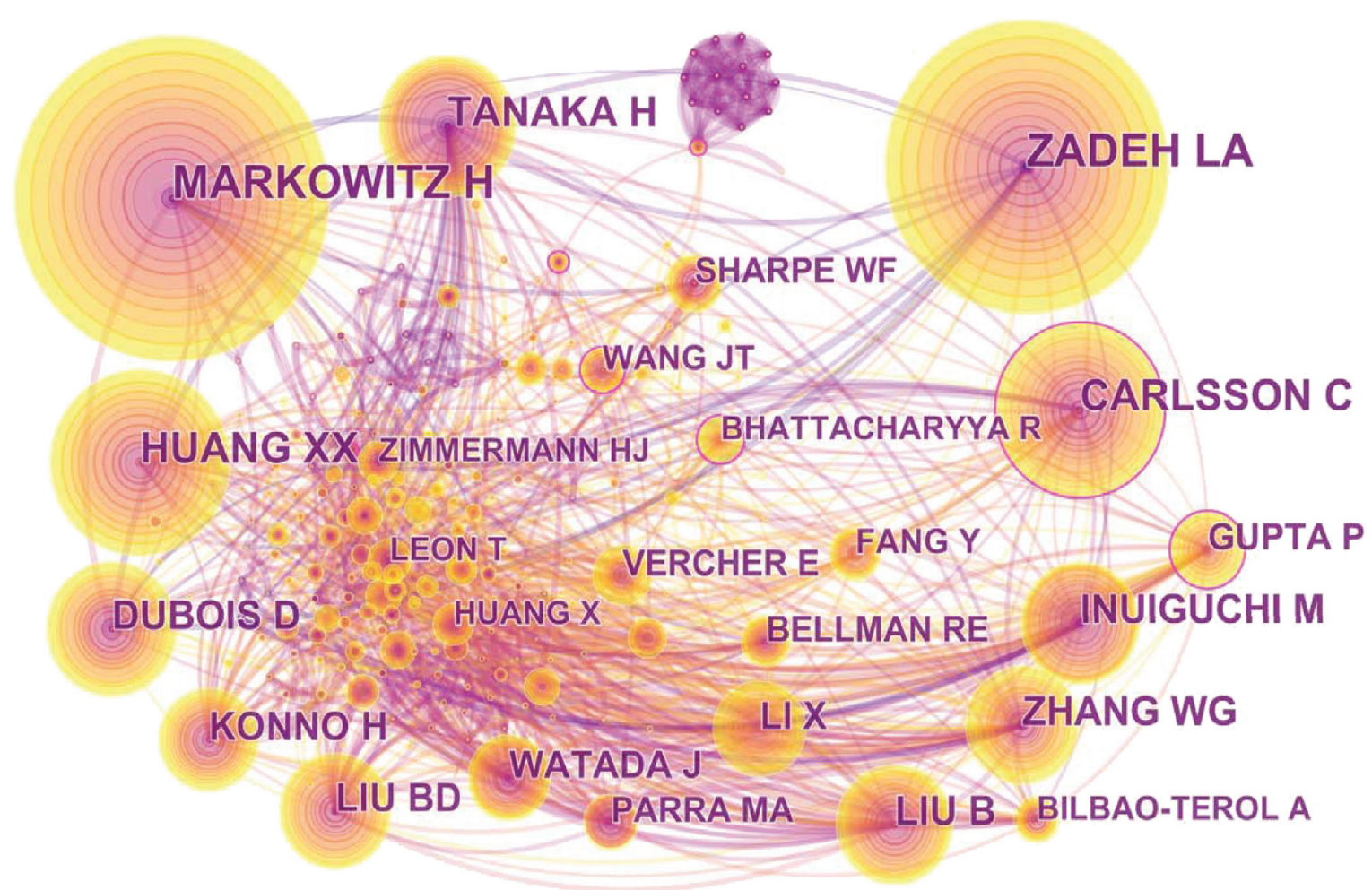

FIGURE 5: A visualization of the cited author collaboration network.

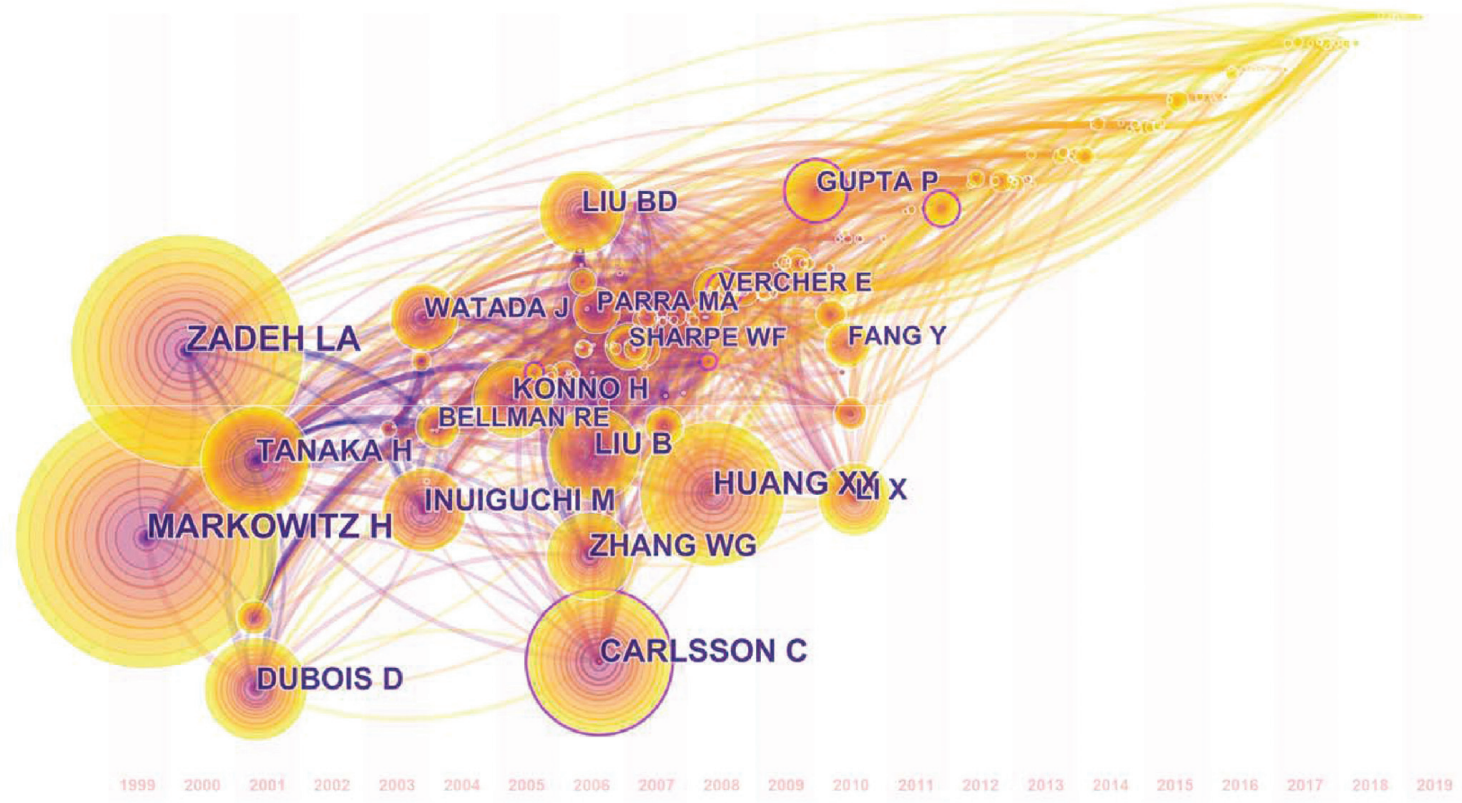

Figure 6: Time zone view of the cited author.

By building a knowledge map network of countries, the collaboration relationships of countries are identified. Figure 8 contains 29 nodes and 47 connections. Each node represents a country, and the larger the radius of the circle, the greater the number of related articles published in the country. The connection between nodes indicates the cooperation between countries. It can be seen from Figure 8 that the cooperation between countries in the world of fuzzy portfolio research is relatively concentrated, and the cooperation between countries is relatively close. Only a few countries have relatively independent research in this field, such as Russia. Meanwhile, this result is in accordance with the analysis of institutions which highlight the impact of China in the fuzzy portfolio field. In addition, the outermost 


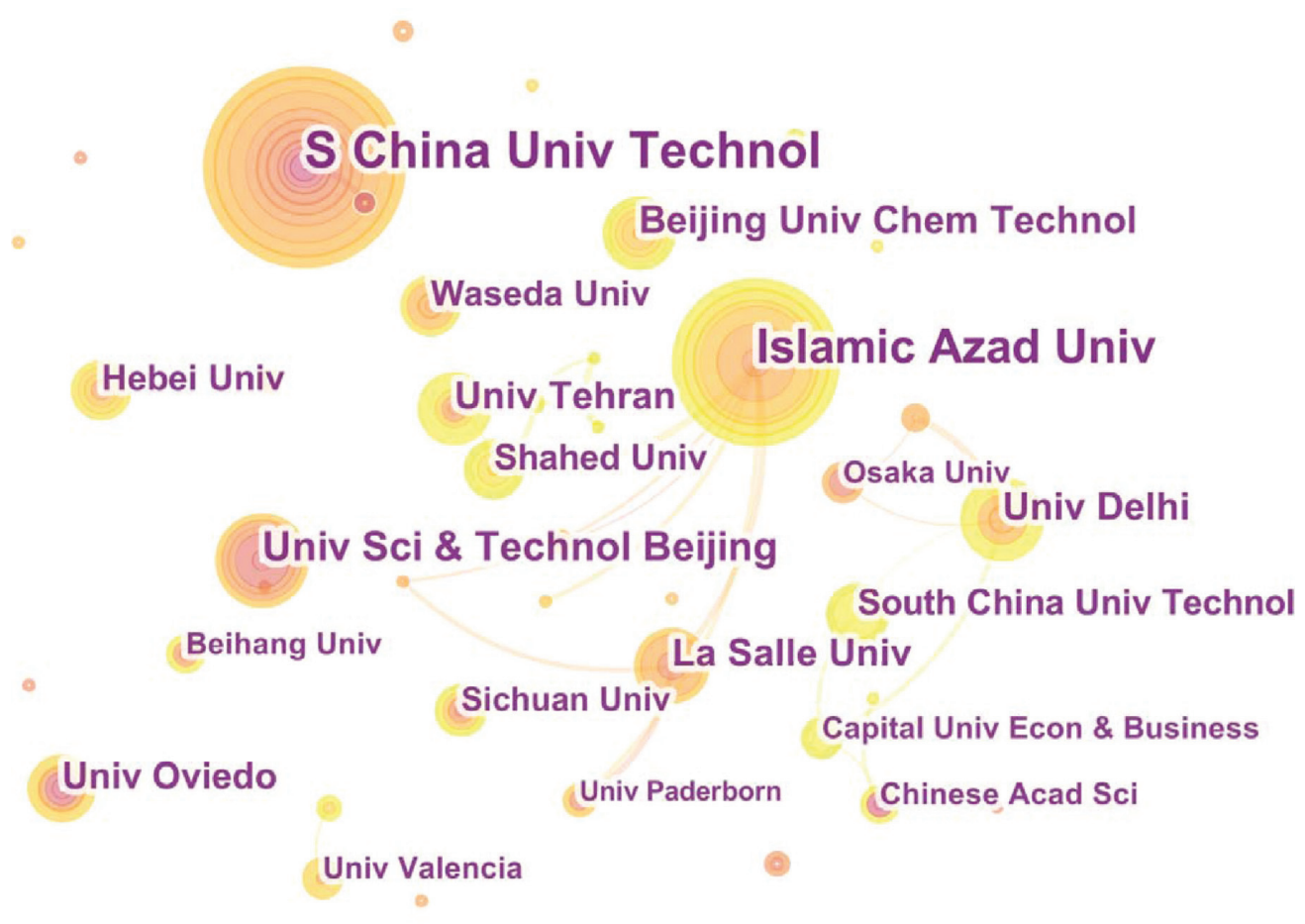

FIGURE 7: A visualization of the institution collaboration network.

TABLE 6: Top 20 most productive institutions.

\begin{tabular}{|c|c|c|c|}
\hline Institution & Country & Frequency & Centrality \\
\hline South China University of Technology & China & 38 & 0.01 \\
\hline Islamic Azad University & Iran & 23 & 0.01 \\
\hline Shahed University & Iran & 17 & 0.00 \\
\hline University of Delhi & India & 16 & 0.01 \\
\hline University of Science and Technology Beijing & China & 14 & 0.00 \\
\hline Hebei University & China & 14 & 0.00 \\
\hline Capital University of Economics and Business & China & 12 & 0.02 \\
\hline Waseda University & Japan & 12 & 0.00 \\
\hline Chinese Academy of Sciences & China & 12 & 0.04 \\
\hline University of Oviedo & Spain & 12 & 0.00 \\
\hline Beijing University of Chemical Technology & China & 12 & 0.01 \\
\hline Sichuan University & China & 11 & 0.02 \\
\hline University of Tehran & Iran & 11 & 0.00 \\
\hline Osaka University & Japan & 11 & 0.01 \\
\hline Beihang University & China & 10 & 0.01 \\
\hline Amirkabir University of Technology & America & 10 & 0.00 \\
\hline University of Valencia & Spain & 9 & 0.00 \\
\hline La Salle University & France & 8 & 0.00 \\
\hline Iran University of Science \& Technology & Iran & 8 & 0.00 \\
\hline City University of Hong Kong & China & 7 & 0.02 \\
\hline
\end{tabular}

purple circle of the node indicates the central position of each country. It represents the ratio of the shortest path through the node in the shortest path between all other vertices in the network. If the ratio is large, the purple circle is thicker, indicating that the node has a higher centrality, and the country has a higher status in the field of research. It can be intuitively observed from Figure 8 that the node representing Spain has the thickest purple circle and the centrality of Spain is 0.43 . Other countries with a purple aperture include China (0.32), the United States (0.31), Iran (0.26), and Canada (0.22), which means that these countries have a strong influence on the network structure, and the mediating role in this field is most significant.

The top 20 productive countries captured by CiteSpace are listed in Table 7 . In terms of the number of articles published, China has the highest contribution rate of 
TABle 7: Top 20 most productive countries.

\begin{tabular}{lccc}
\hline Country & Frequency & Centrality & Year \\
\hline The People's Republic of China & 199 & 0.32 & 2002 \\
Iran & 79 & 0.26 & 2008 \\
Spain & 53 & 0.43 & 2001 \\
Taiwan & 46 & 0.08 & 2004 \\
India & 43 & 0.05 & 2008 \\
United States & 42 & 0.31 & 1996 \\
Japan & 36 & 0.06 & 1998 \\
Turkey & 22 & 0.01 & 2005 \\
Australia & 19 & 0.04 & 2005 \\
Canada & 17 & 0.22 & 2000 \\
Romania & 16 & 0.02 & 1999 \\
England & 15 & 0.12 & 2002 \\
Germany & 15 & 0.02 & 1999 \\
Brazil & 14 & 0.00 & 2012 \\
France & 12 & 0.10 & 2009 \\
Italy & 11 & 0.11 & 2006 \\
Mexico & 11 & 0.00 & 2002 \\
Lithuania & 10 & 0.01 & 2012 \\
Poland & 9 & 0.01 & 2012 \\
Finland & 8 & 0.01 & 2009 \\
\hline
\end{tabular}

literature, followed by Iran (79), Spain (53), Taiwan (46), India (43), and the United States (42). Among the total 677 papers, 199 publications are from China which is nearly a third of sample size. Both the number of publications from China and the centrality of China are high. Tremendous achievement of China in the research of fuzzy portfolio benefits from the rapid development of China's financial industry. The increase in national wealth has led to an increase in portfolio investment demand.

\section{Mapping and Analysis on Keywords, References, and Journals}

5.1. Keyword Analysis. As the key to revealing the content of the article, keywords are an essential part of article analysis. Long-term keyword analysis in academic research can reveal the content characteristics, development context, and development status of research results. In order to know the hot spot of fuzzy portfolio research, we make a keyword analysis.

Table 8 gives information about the keywords with the appearance frequency in the top 20 . The result is counted by CiteSpace. As can be seen from Table 8, "model" is the most frequently occurring keyword and "portfolio selection" is the second. This result is consistent with the results we envisioned in the keyword "fuzzy portfolio." Applying fuzzy logic to the ratio of portfolios is a good way to achieve investment portfolio construction. Through a comprehensive analysis of keywords, we can find it is the focus of scholars to study the relationship between portfolio selection and optimization through a mathematical model. On the other hand, appearing frequency of "possibility distribution" is 57 . When assessing investment portfolio risks, it is very common to apply two analytical methods for describing parameter uncertainty: probability distribution and possibility distribution.
TABle 8: Top 20 keywords of fuzzy portfolio research.

\begin{tabular}{lcc}
\hline Keyword & Frequency & Year \\
\hline Model & 165 & 2001 \\
Portfolio selection & 155 & 1998 \\
Optimization & 126 & 2000 \\
Risk & 75 & 2003 \\
Selection & 75 & 2009 \\
Variance & 73 & 2006 \\
Algorithm & 64 & 2004 \\
Management & 58 & 2009 \\
System & 45 & 1996 \\
Decision making & 41 & 2008 \\
Genetic algorithm & 39 & 2000 \\
Uncertainty & 37 & 2000 \\
Fuzzy number & 36 & 2001 \\
Performance & 36 & 2009 \\
Return & 35 & 2011 \\
Fuzzy set & 35 & 1999 \\
Fuzzy & 31 & 2001 \\
Number & 29 & 2000 \\
Portfolio optimization & 29 & 1996 \\
Portfolio & 49 & 0.01 \\
\hline
\end{tabular}

Citation bursts, which refer to articles that have sharply increased in citations, can reflect the dynamics of a field. The top 10 keywords with the strongest citation bursts are reflected in Table 9. The last column of the line means the entire year of the study (1996-2020), and the red line represents the duration of the keyword outbreak. According to Table 9, "possibility distribution" with bursts of 7.2369 ranks first, followed by "portfolio selection" with bursts of 5.1301, occupying the third position is "variable" (4.4277), followed by "project selection" (3.9506), "fuzzy set" (3.8966), "neural network" (3.8459), "fuzzy random variable" (3.6141), and "finance" (3.604). Their burst strength is all above 3.5 .

The earliest citation burst started in 1999, which is consistent with the start-up phase of fuzzy portfolio research. In the 90 s of the last century, "fuzzy set" is the mainstream trend of the fuzzy portfolio research area. However, "project selection," "variable," and "fuzzy random variable" have become the research frontier in recent years. From 1996 to 2020, researchers focused on developing a group decision-making approach to help managers to select optimal portfolio [42] and using semivariance as a risk measure integrated with investor's judgment on assets' future performance [43].

5.2. Reference Analysis. CiteSpace can transform traditional descriptive expressions into visualizations. Cocitation refers to the relationship between two articles when they are simultaneously cited by the third article published later, which reflects the correlation between cited documents in research topics. In the process of its evolution, this correlation gradually changed from research frontier to research foundation in the research field of fuzzy portfolio.

Figure 9 describes the cocitation analysis of fuzzy portfolio research. Each node represents an article that is cited in the top. The larger the node radius, the more times it 


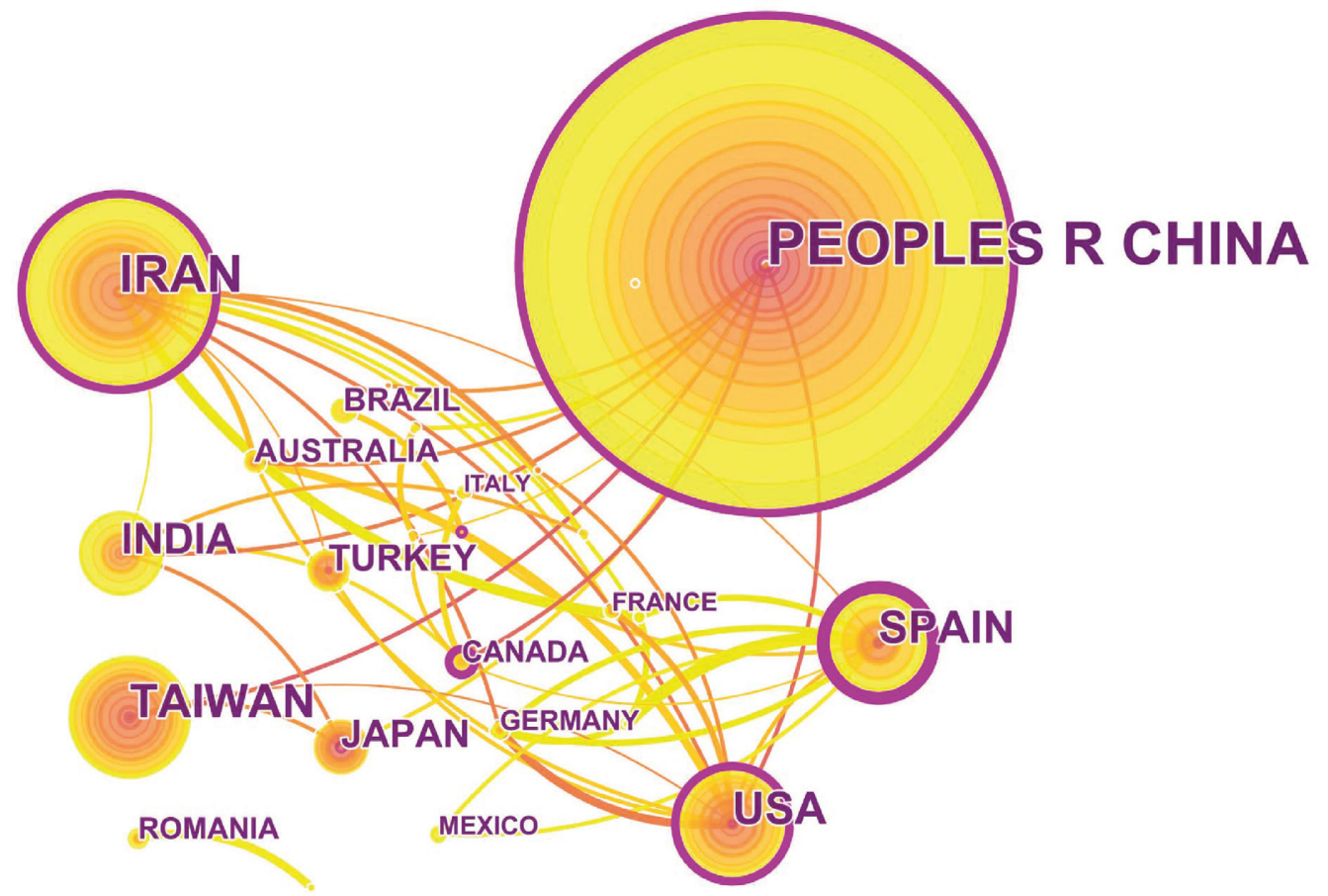

FIGURE 8: A visualization of the country collaboration network.

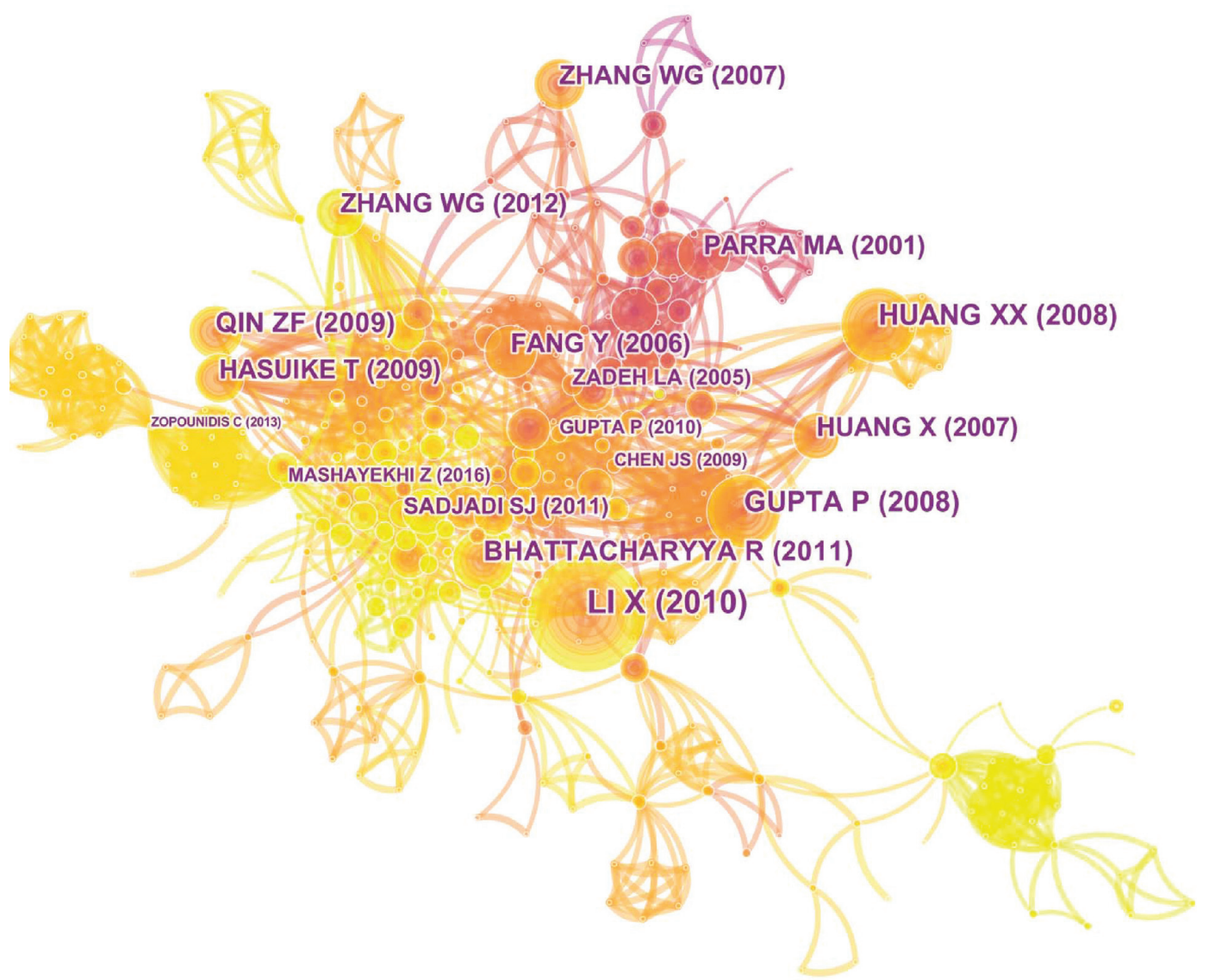

FIgURe 9: Papers with important academic value in the fuzzy portfolio research. 
TABLE 9: Top 10 keywords based on burst strength in the fuzzy portfolio research.

\begin{tabular}{|c|c|c|c|c|}
\hline Keywords & Strength & Begin & End & 1996-2020 \\
\hline Possibility distribution & 7.2369 & 2005 & 2009 & . \\
\hline Portfolio selection & 5.1301 & 2006 & 2009 & \\
\hline Variable & 4.4277 & 2007 & 2012 & \\
\hline Project selection & 3.9506 & 2012 & 2016 & \\
\hline Fuzzy set & 3.8966 & 1999 & 2007 & \\
\hline Neural network & 3.8459 & 2009 & 2011 & \\
\hline Fuzzy random variable & 3.6141 & 2008 & 2012 & \\
\hline Finance & 3.604 & 2002 & 2007 & \\
\hline Fuzzy programming & 3.4467 & 2001 & 2008 & \\
\hline Transaction cost & 3.4109 & 2007 & 2011 & \\
\hline
\end{tabular}

is cited. Node connections represent the relationship between articles. The complexity of the connection indicates that the references between the articles are closely related in Figure 9. The frequency of article by Huang in the above picture is high. In the research of fuzzy portfolio, Huang is worthy of scholars' attention, which is consistent with the result of the cited author analysis. Huang [32] proposed two mean-semivariance models to solve the problem of portfolio selection in fuzzy environment. Huang [36] provided two types of credibility-based portfolio selection model according to two types of chance criteria. Li et al. [24] presented a mean-variance-skewness model and designed a genetic algorithm integrating fuzzy simulation to measure the asymmetry of fuzzy portfolio return. Carlsson et al. [5] presented a fuzzy mixed integer programming model for the R\&D optimal portfolio selection. Parra et al. [21] applied a fuzzy GP approach to deal with the relationship between income, risk, and liquidity.

Using multivariate statistical analysis methods (such as cluster analysis), the complex cocitation network relationships between the analyzed objects are divided into a few of groups visually presented through CiteSpace. The results obtained after the document clustering are displayed in the form of a timeline and are shown in Figure 10. The color of the ring from cooling to warmth reflects the advancement of knowledge in the field. The yellow citation tree ring is the current research hotspot. The entire network is divided into 13 clusters, and these labeled clusters are summarized with "\#” on the right side of Figure 10. This cluster uses heading terms and log likelihood ratio (LLR) weighting algorithms to mark clusters. LLR is an algorithm for calculating and determining each type of tag, which presents the core concepts of each cluster in professional vocabulary [44]. These major clusters extracted with "\#” reflect the forefront of the development of the research of fuzzy portfolio. Therefore, "multiperiod portfolio selection," "bounds of variance," "fuzzy variable," "portfolio adjusting," "hybrid intelligence," "fuzzy logic," "multicriteria decision analysis," "fuzzy integer linear programming," "Sharpe's single-index model," and "capital asset pricing model" are the main research area in the knowledge field of fuzzy portfolio. In detail, the top 10 clusters are summarized in Table 10. Size refers to the number of articles included in one cluster. Silhouette is a number used to measure the degree of cluster homogeneity, and the higher the silhouette, the higher the degree of homogenization. When the silhouette score is greater than or equal to 0.7 , the clustering result is considered to be excellent. The silhouette score of the top 10 clusters listed in Table 10 is almost above 0.7 , implying that these clusters are reliable and convincing. The largest cluster (\#0) has 90 members and a silhouette value of 0.657 . It is labeled as risk control by LLR and its subclusters include "multiperiod portfolio selection (86.46)," "uncertain portfolio selection (46.27)," and "fuzzyANP approach (42.81)". The most active citer to cluster (\#0) is the article named "Fuzzy multi-period portfolio selection optimization models using multiple criteria" written by Liu et al. [45]. The second-largest cluster (\#1) has 73 members and a silhouette value of 0.964 . It is labeled as single-index model by LLR and its subclusters include "project portfolio selection problem (92.14), decades review (49.5)," "sustainability perspective (45.66)," and "type-2 fuzzy environment (45.66)". The most active citer to cluster $(\# 1)$ is the article named "Selecting the optimum portfolio using fuzzy compromise programming and Sharpe's single-index model" written by Bilbao-Terol et al. [46]. The third-largest cluster (\#2) has 68 members and a silhouette value of 0.738 . It is labeled as using semantics by LLR and its subclusters include "fuzzy chance constraint (51.32)," "multiobjective credibilistic portfolio selection model (51.32)," and "uncertain portfolio parameter (45.27)". The most active citer to cluster (\#2) is the article named "Sinvlio: using semantics and fuzzy logic to provide individual investment portfolio recommendations" by García-Crespo et al. [47].

Table 11 shows that the top 20 cited references. It is worth noting that these listed documents are the most cited articles from the 602 publications used in this paper and not from the most cited references in WoS. Among the 20 references listed, the paper entitled "Mean-variance-skewness model for portfolio selection with fuzzy returns" in cluster $(\# 0)$ that published by $\mathrm{Li}$ et al. [24] on European Journal of Operational Research is the most cited paper with 57 citations, followed by the article entitled "Mean-semivariance models for fuzzy portfolio selection" in cluster (\#0) that published by Huang [32] on Journal of Computational and Applied Mathematics which is the second most cited paper with 39 citations. The document entitled "A hybrid approach to asset allocation with simultaneous consideration of suitability and optimality" published by Gupta et al. [48] on Information Sciences is the second most cited reference with 39 citations, too. And the article titled "Fuzzy 


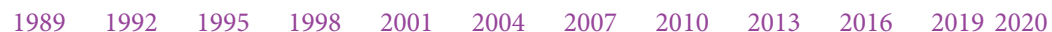

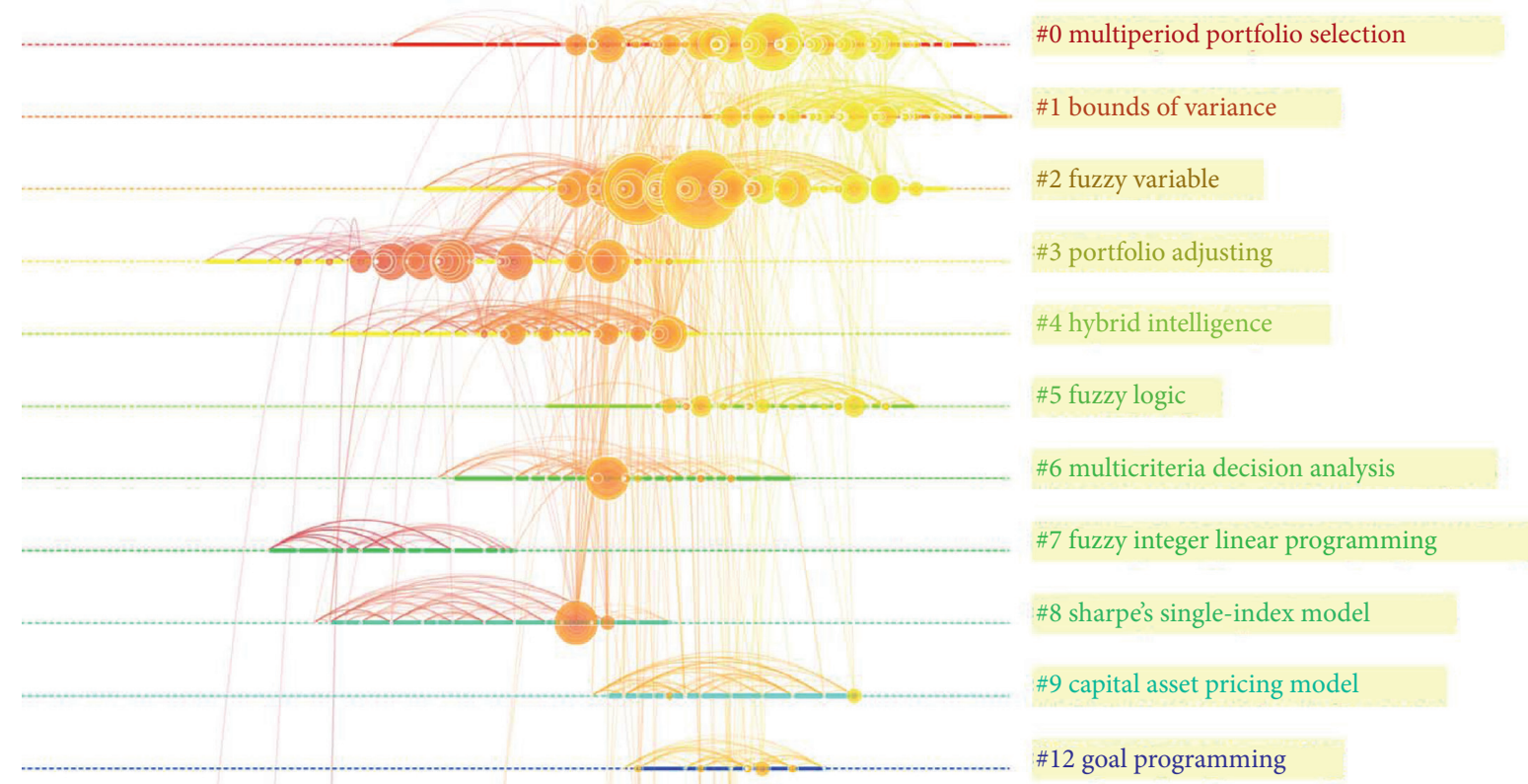

FIGURE 10: A timeline map of the references in the fuzzy portfolio research.

TABLE 10: Top 10 clusters based on size in the fuzzy portfolio research.

\begin{tabular}{lcccc}
\hline Cluster ID & Size & Silhouette score & Label (LLR) & Mean (cite year) \\
\hline 0 & 90 & 0.657 & Multiperiod portfolio selection & 2012 \\
1 & 73 & 0.964 & Bounds of variance & 2015 \\
2 & 68 & 0.738 & Fuzzy variable & 2010 \\
3 & 67 & 0.809 & Portfolio adjusting & 2001 \\
4 & 49 & 0.909 & Hybrid intelligence & 2004 \\
5 & 42 & Fuzzy logic & 2012 \\
6 & 40 & 0.834 & Multicriteria decision analysis & 2007 \\
7 & 34 & 0.885 & Fuzzy integer linear programming & 1999 \\
8 & 30 & Sharpe's single-index model & 2002 \\
9 & 24 & Capital asset pricing model & 2015 \\
\hline
\end{tabular}

R\&D portfolio selection of interdependent projects" published by Bhattacharyya et al. [49] on Computers \& Mathematics with Applications is the third most cited reference with 32 citations. In addition, nearly half of the articles in the top 20 most cited articles belong to cluster (\#0), which means that risk control is the focus of research of the fuzzy portfolio.

From the above analysis, it can be concluded that the highly cited articles in the research field of fuzzy portfolio mainly focus on building a new model or algorithm to solve the problem of portfolio selection in actual situations. In addition, these articles have been published in the previous year, indicating that early published articles have farreaching implications for current research. Based on the above conclusions, the author infers that scholars are studying new research methods in this field.

5.3. Journal Analysis. When two journals are simultaneously cited by other journals, there is a journal-cited relationship between the two journals. Cocitation analysis of journals helps to identify core journals at the forefront of research in specific research areas. The focus of core journals represents the most advanced research direction, which can provide useful information for follow-up scholars. The mapping and analysis of journals are as follows.

Figure 11 consists of 210 nodes and 1085 links, which represent there are 210 journals in the map and 1085 cited times between these journals. The larger the radius of the circle, the more times the journal is cited.

As can be seen from Table 12, European Journal of Operations Research has the highest frequency of citations up to 446 times. The centrality of European Journal of Operations Research is 0.03 . The impact factor of this journal is 3.806, which indicates that the journal holds a very important position in the research of fuzzy portfolio. European Journal of Operations Research is the cradle of a large number of crucial fuzzy portfolio research results. The most cited articles published by European Journal of Operations Research include "A fuzzy goal programming approach to 
TABLE 11: Top 20 references based on frequency in the fuzzy portfolio research.

\begin{tabular}{|c|c|c|c|c|}
\hline Title & Authors & Frequency & Source & Year \\
\hline $\begin{array}{l}\text { Mean-variance-skewness model for portfolio selection with } \\
\text { fuzzy returns [24] }\end{array}$ & Li et al. & 57 & $\begin{array}{c}\text { European Journal of Operational } \\
\text { Research }\end{array}$ & 2010 \\
\hline $\begin{array}{l}\text { A hybrid approach to asset allocation with simultaneous } \\
\text { consideration of suitability and optimality [48] }\end{array}$ & Gupta et al. & 39 & Information Sciences & 2010 \\
\hline Mean-semivariance models for fuzzy portfolio selection [32] & Huang & 39 & $\begin{array}{l}\text { Journal of Computational and } \\
\text { Applied Mathematics }\end{array}$ & 2008 \\
\hline Fuzzy R\&D portfolio selection of interdependent projects [49] & $\begin{array}{l}\text { Bhattacharyya } \\
\text { et al. }\end{array}$ & 32 & $\begin{array}{c}\text { Computers \& Mathematics with } \\
\text { Applications }\end{array}$ & 2011 \\
\hline $\begin{array}{l}\text { A possibilistic mean-semivariance-entropy model for multi- } \\
\text { period portfolio selection with transaction costs [25] }\end{array}$ & Zhang et al. & 31 & $\begin{array}{c}\text { European Journal of Operational } \\
\text { Research }\end{array}$ & 2012 \\
\hline Portfolio selection based on fuzzy cross-entropy [50] & Qin et al. & 30 & $\begin{array}{l}\text { Journal of Computational \& } \\
\text { Applied Mathematics }\end{array}$ & 2009 \\
\hline $\begin{array}{l}\text { Selecting the optimum portfolio using fuzzy compromise } \\
\text { programming and Sharpe's single-index model [46] }\end{array}$ & $\begin{array}{c}\text { Bilbao } \\
\text { et }\end{array}$ & 29 & $\begin{array}{l}\text { Applied Mathematics and } \\
\text { Computation }\end{array}$ & 2006 \\
\hline A review of uncertain portfolio selection [51] & Huang et al. & 27 & $\begin{array}{c}\text { Journal of Intelligent and Fuzzy } \\
\text { Systems }\end{array}$ & 2017 \\
\hline dels and efficient frontiers for & Zhar & 27 & Information Sciences & 2007 \\
\hline $\begin{array}{l}\text { Portfolio selection problems with random fuzzy variable returns } \\
\text { [52] }\end{array}$ & Hasuike et al. & 27 & Fuzzy Sets and Systems & 2009 \\
\hline A fuzzy goal programming approach to portfolio selection [21] & Parr & 26 & $\begin{array}{r}\text { European Jour } \\
\operatorname{Re}\end{array}$ & 2001 \\
\hline $\begin{array}{l}\text { Portfolio rebalancing model with transaction costs based on } \\
\text { fuzzy decision theory [6] }\end{array}$ & Fang et al. & 25 & $\begin{array}{c}\text { European Journal of Operational } \\
\text { Research }\end{array}$ & 2006 \\
\hline $\begin{array}{l}\text { Portfolio selection based on fuzzy probabilities and possibility } \\
\text { distributions [20] }\end{array}$ & Tana & 23 & Fuzzy Sets and Sy & 2000 \\
\hline $\begin{array}{l}\text { A fuzzy set approach for } R \& D \text { portfolio selection using a real } \\
\text { options valuation model }[22]\end{array}$ & $\begin{array}{l}\text { Wang and } \\
\text { Hwang }\end{array}$ & 23 & $\begin{array}{l}\text { Omega-interna } \\
\text { Managem }\end{array}$ & 2007 \\
\hline Special issue: Soft decision analysis-preface [53] & $\begin{array}{l}\text { Carlsson and } \\
\text { Fuller }\end{array}$ & 23 & Sets and Systems & 2002 \\
\hline On admissible efficient portfolio selection problem [54] & Zhang and Nie & 22 & $\begin{array}{l}\text { Applied Mathematics and } \\
\text { Computation }\end{array}$ & 2004 \\
\hline $\begin{array}{l}\text { A multi-objective genetic algorithm for cardinality constrained } \\
\text { fuzzy portfolio selection [55] }\end{array}$ & Bermudez et al. & 21 & Fuzzy Sets and Systems & 2012 \\
\hline $\begin{array}{l}\text { Multiobjective credibilistic portfolio selection model with fuzzy } \\
\text { chance-constraints [56] }\end{array}$ & Gupta et al. & 21 & Information Sciences & 2013 \\
\hline Mean-entropy models for fuzzy portfolio selection [39] & Huang & 21 & $\begin{array}{l}\text { IEEE Transactions on Fuzzy } \\
\text { Systems }\end{array}$ & 2008 \\
\hline $\begin{array}{l}\text { Portfolio selection based on upper and lower exponential } \\
\text { possibility distributions [3] }\end{array}$ & Tanaka and Guo & 21 & $\begin{array}{c}\text { European Journal of Operational } \\
\text { Research }\end{array}$ & 1999 \\
\hline
\end{tabular}

portfolio selection," "Portfolio selection based on upper and lower exponential possibility distributions," and "Meanvariance-skewness model for portfolio selection with fuzzy returns." In addition, the citation frequency of the Fuzzy Sets and Systems is as high as 414. The impact factor is 2.675. Fuzzy Sets and Systems also has outstanding performance in the research of fuzzy portfolio. "Possibilistic linear programming: a brief review of fuzzy mathematical programming and a comparison with stochastic programming in portfolio selection problem," "Portfolio selection based on fuzzy probabilities and possibility distributions," and "Fuzzy portfolio optimization under downside risk measures" are the most cited documents published by Fuzzy Sets and Systems. Moreover, The Journal of Finance (5.397) and IEEE Transactions on Fuzzy Systems (8.415) also have a very high impact factor and can be considered a core journal in the research field of fuzzy portfolio. The article titled "Mean- entropy models for fuzzy portfolio selection" written by Huang [39] is most cited document published by IEEE Transactions on Fuzzy Systems. Besides, though the impact factor is low, Information and Control has a high frequency of reference (192) and centrality (0.06), which indicates that this journal also plays a crucial role in the research field of fuzzy portfolio. The document titled "fuzzy sets" published by Zadeh [40] on Information and Control makes a great contribution on high frequency of reference of the journal. In terms of time distribution, the cited time of all highfrequency cited journals is distributed in 1996-2005, which illustrates that articles published in these journals between 1996 and 2005 have far-reaching implications for current research. Studying documents related to the fuzzy portfolio published in these core journals will help to accurately grasp the trends and frontiers of the research, thus indicating further research directions for relevant scholars. 


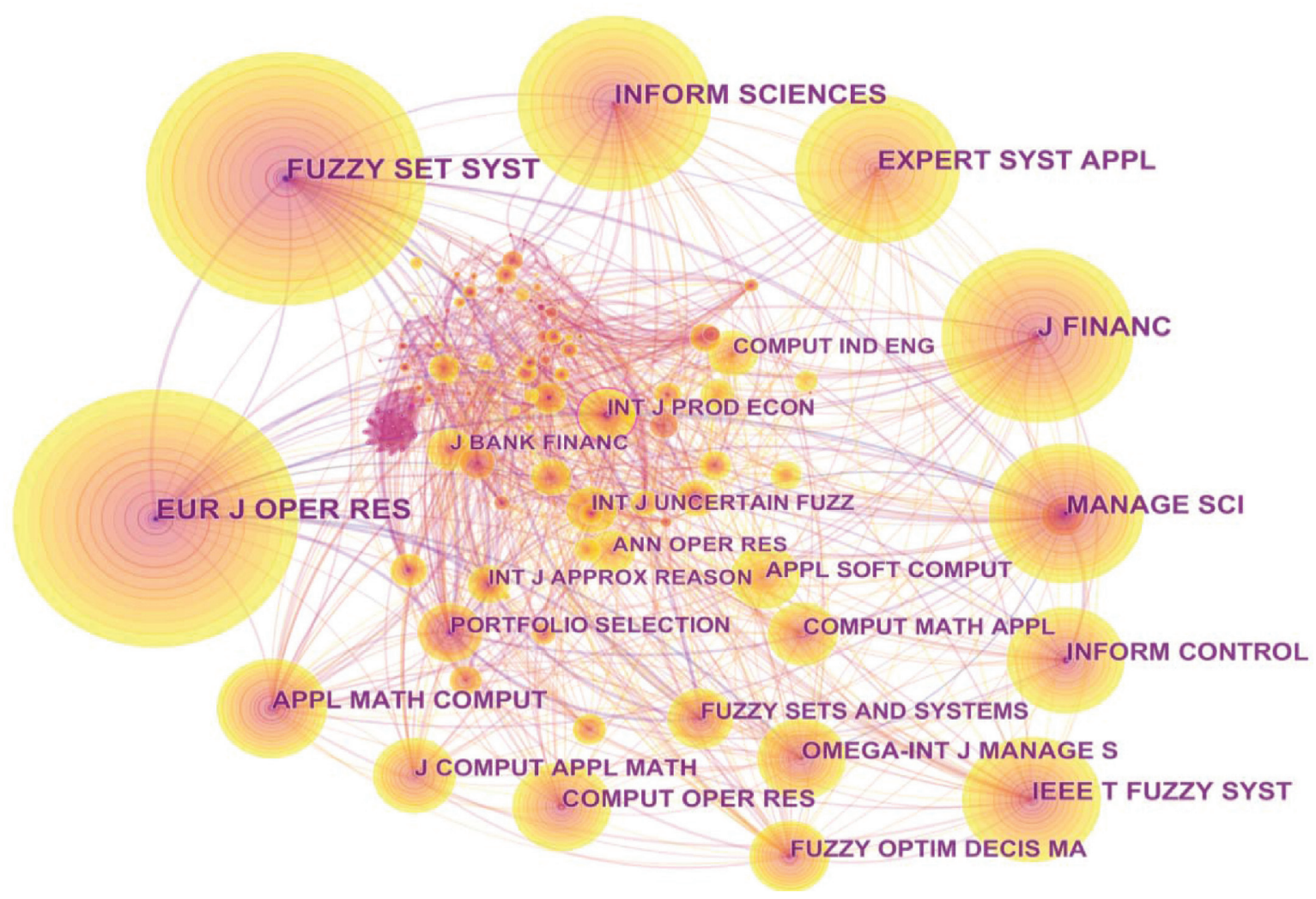

Figure 11: Map of journal cocitation.

TABLE 12: Top 10 most cited journals based on frequency in the fuzzy portfolio research.

\begin{tabular}{lcccc}
\hline Count & Centrality & year & Cited journal & Impact factor \\
\hline 446 & 0.03 & 1996 & European Journal of Operational Research & 3.806 \\
414 & 0.06 & 1999 & Fuzzy Sets and Systems & 2.675 \\
316 & 0.05 & 2003 & Information Sciences & 4.305 \\
300 & 0.06 & 2002 & The Journal of Finance & 5.397 \\
289 & 0.04 & 2005 & Expert Systems with Applications & 3.768 \\
246 & 0.04 & 1996 & Manage Science & 3.544 \\
237 & 0.03 & 2006 & IEEE Transactions on Fuzzy Systems & 8.415 \\
192 & 0.06 & 1999 & Information and Control & 0.913 \\
187 & 0.05 & 2005 & Computer and Operations Research & 2.962 \\
179 & 0.05 & 2005 & & 2.3 \\
\hline
\end{tabular}

\section{Conclusions}

This analysis, basing on CiteSpace of bibliometrics record from the field of fuzzy portfolio, has provided a unique and interest snapshot of fuzzy portfolio knowledge domain. Through a visual analysis of country and institution distribution, keyword co-occurrence, literature cocitation, and journal cocitation, this paper has provided important reference for future research in this field. According to systematic review of visual knowledge maps and research results in the field of fuzzy portfolios, a number of conclusions have been drawn from the results as follows. First of all, the document on the fuzzy portfolio research area has increased significantly and research on fuzzy portfolio has been more and more scattered. In addition, Zhang has become the author with the largest number of articles published, and Zadeh has been the author with the most citations. The authors with most articles may have not been cited most frequently. Besides, China has been the most productive country and South China University Technology has become the most productive institution. Furthermore, European Journal of Operations Research has been the cradle of a large number of crucial fuzzy portfolio investigations. At last, we have found the keyword with the highest frequency of occurrence has been "model" and scholars have trended to build a model to achieve investment portfolio optimization. Apart from this, "project selection," "variable," and "fuzzy random variable" has become the research hotspots in recent years. In short, this paper has identified the potential relationships between documents through bibliometric analysis and has clarified the knowledge evolution of fuzzy portfolios. Helping scholars in the field of fuzzy portfolios to 
conduct large-scale knowledge combing and providing reading directions for novices with strong interest have been the purpose of this research. There are several problems in this paper. For instance, the selection of the threshold is the default value, and the debugging of the network structure needs further exploration. Therefore, in future research of bibliometrics, we should improve the extensiveness of data sources, fully combine the data of major databases, select appropriate thresholds, compare the research of countries, and comb the development trend of the research. Moreover, whether the author is a visitor researcher or fellow is excluded in our consideration. Therefore, we will strive to improve the result accuracy in further investigations.

\section{Data Availability}

The data used to support the findings of this study are included within the supplementary information files.

\section{Conflicts of Interest}

The authors declare that they have no conflicts of interest.

\section{Acknowledgments}

This work was supported by the Natural Science Foundation of China (nos. 71561026, 71840001, and 71764033) and Yunnan Fundamental Research Projects (no. 2017FB101).

\section{Supplementary Materials}

This section includes references of data used in this study. (Supplementary Materials)

\section{References}

[1] L. A. Zadeh, "Fuzzy sets as a basis for a theory of possibility," Fuzzy Sets and Systems, vol. 1, no. 1, pp. 3-28, 1978.

[2] R. Östermark, "A fuzzy control model (FCM) for dynamic portfolio management," Fuzzy Sets and Systems, vol. 78, no. 3, pp. 243-254, 1996.

[3] H. Tanaka and P. Guo, "Portfolio selection based on upper and lower exponential possibility distributions," European Journal of Operational Research, vol. 114, no. 1, pp. 115-126, 1999.

[4] T. León, V. Liern, and E. Vercher, "Viability of infeasible portfolio selection problems: a fuzzy approach," European Journal of Operational Research, vol. 139, no. 1, pp. 178-189, 2002.

[5] C. Carlsson, R. Fullér, and P. Majlender, "A possibilistic approach to selecting portfolios with highest utility score," Fuzzy Sets and Systems, vol. 131, no. 1, pp. 13-21, 2002.

[6] Y. Fang, K. K. Lai, and S.-Y. Wang, "Portfolio rebalancing model with transaction costs based on fuzzy decision theory," European Journal of Operational Research, vol. 175, no. 2, pp. 879-893, 2006.

[7] F. Tiryaki and B. Ahlatcioglu, "Fuzzy portfolio selection using fuzzy analytic hierarchy process," Information Sciences, vol. 179, no. 1-2, pp. 53-69, 2009.

[8] W.-G. Zhang and W.-L. Xiao, "On weighted lower and upper possibilistic means and variances of fuzzy numbers and its application in decision," Knowledge and Information Systems, vol. 18, no. 3, pp. 311-330, 2009.

[9] A. F. D. Silva, R. D. C. Miranda, and F. A. S. Marins, "Um modelo fuzzy-dea-game para estratégias de produção sob incerteza," Revista de Administração de Empresas, vol. 55, no. 1, pp. 78-94, 2015.

[10] W. Yue and Y. Wang, "A new fuzzy multi-objective higher order moment portfolio selection model for diversified portfolios," Physica A: Statistical Mechanics and Its Applications, vol. 465, pp. 124-140, 2017.

[11] W. Chen, Y. Wang, and M. K. Mehlawat, "A hybrid FA-SA algorithm for fuzzy portfolio selection with transaction costs," Annals of Operations Research, vol. 269, no. 1-2, pp. 129-147, 2018.

[12] Y.-J. Liu, W.-G. Zhang, and X.-J. Zhao, "Fuzzy multi-period portfolio selection model with discounted transaction costs," Soft Computing, vol. 22, no. 1, pp. 177-193, 2018.

[13] Y. J. Liu and W. G. Zhang, "Possibilistic moment models for multi-period portfolio selection with fuzzy returns," Computational Economics, vol. 53, no. 4, pp. 1857-1686, 2018.

[14] F. Alali and A. C. Tolga, "Portfolio allocation with the TODIM method," Expert Systems with Applications, vol. 124, pp. 341-348, 2019.

[15] C. M. Chen, "Citespace II: detecting and visualizing emerging trends and transient patterns in scientific literature," Journal of the Association for Information Science \& Technology, vol. 57, no. 3, pp. 359-377, 2014.

[16] C. J. Rang and C. Zeng, "Visual analysis of the Chinese finance studies in recent ten years," Journal of Information Resources Management, vol. 4, no. 1, pp. 29-36, 2014.

[17] D. F. Costa, F. de Melo Carvalho, B. C. de Melo Moreira, and J. W. do Prado, "Bibliometric analysis on the association between behavioral finance and decision making with cognitive biases such as overconfidence, anchoring effect and confirmation bias," Scientometrics, vol. 111, no. 3, pp. 1775-1799, 2017.

[18] X. Xu, X. Chen, F. Jia, S. Brown, Y. Gong, and Y. Xu, “chain finance: a systematic literature review and bibliometric analysis," International Journal of Production Economics, vol. 204, pp. 160-173, 2018.

[19] M. Inuiguchi and J. Ramík, "Possibilistic linear programming: a brief review of fuzzy mathematical programming and a comparison with stochastic programming in portfolio selection problem," Fuzzy Sets and Systems, vol. 111, no. 1, pp. 3-28, 2000.

[20] H. Tanaka, P. Guo, and I. B. Türksen, "Portfolio selection based on fuzzy probabilities and possibility distributions," Fuzzy Sets and Systems, vol. 111, no. 3, pp. 387-397, 2000.

[21] M. A. Parra, A. B. Terol, and M. V. R. Uria, "A fuzzy goal programming approach to portfolio selection," European Journal of Operational Research, vol. 133, no. 2, pp. 287-297, 2001.

[22] J. Wang and W.-L. Hwang, "A fuzzy set approach for R\&D portfolio selection using a real options valuation model," Omega, vol. 35, no. 3, pp. 247-257, 2007.

[23] M. P. Amiri, "Project selection for oil-fields development by using the AHP and fuzzy topsis methods," Expert Systems with Applications, vol. 37, no. 9, pp. 6218-6224, 2010.

[24] X. Li, Z. Qin, and S. Kar, "Mean-variance-skewness model for portfolio selection with fuzzy returns," European Journal of Operational Research, vol. 202, no. 1, pp. 239-247, 2010.

[25] W.-G. Zhang, Y.-J. Liu, and W.-J. Xu, “A possibilistic meansemivariance-entropy model for multi-period portfolio selection with transaction costs," European Journal of Operational Research, vol. 222, no. 2, pp. 341-349, 2012. 
[26] P. Gupta, M. K. Mehlawat, and A. Saxena, "Asset portfolio optimization using fuzzy mathematical programming," Information Sciences, vol. 178, no. 6, pp. 1734-1755, 2008.

[27] R. G. Coopper, "Perspective-3rd-Generation new product processes," Journal of Product Innovation Management, vol. 11, no. 1, pp. 3-14, 1994.

[28] A. Khurana and S. R. Rosenthal, "Integrating the fuzzy front end of new product development," Sloan Management Review, vol. 38, no. 2, pp. 103-120, 1997.

[29] S. Ebrahimnejad, S. M. Mousavi, R. Tavakkoli-Moghaddam, H. Hashemi, and B. Vahdani, "A novel two-phase group decision making approach for construction project selection in a fuzzy environment," Applied Mathematical Modelling, vol. 36, no. 9, pp. 4197-4217, 2012.

[30] A. Bahrammirzaee, "A comparative survey of artificial intelligence applications in finance: artificial neural networks, expert system and hybrid intelligent systems," Neural Computing and Applications, vol. 19, no. 8, pp. 1165-1195, 2010.

[31] C. Carlsson, R. Fullér, M. Heikkilä, and P. Majlender, "A fuzzy approach to $\mathrm{R} \& \mathrm{D}$ project portfolio selection," International Journal of Approximate Reasoning, vol. 44, no. 2, pp. 93-105, 2007.

[32] X. Huang, "Mean-semivariance models for fuzzy portfolio selection," Journal of Computational and Applied Mathematics, vol. 217, no. 1, pp. 1-8, 2008.

[33] E. Vercher, J. D. Bermúdez, J. V. Segura, and J. V. Segurab, "Fuzzy portfolio optimization under downside risk measures," Fuzzy Sets and Systems, vol. 158, no. 7, pp. 769-782, 2007.

[34] C.-C. Lin and Y.-T. Liu, "Genetic algorithms for portfolio selection problems with minimum transaction lots," European Journal of Operational Research, vol. 185, no. 1, pp. 393-404, 2008.

[35] J. Jiao and Y. Zhang, "Product portfolio identification based on association rule mining," Computer-Aided Design, vol. 37, no. 2, pp. 149-172, 2005.

[36] X. Huang, "Fuzzy chance-constrained portfolio selection," Applied Mathematics and Computation, vol. 177, no. 2, pp. 500-507, 2006.

[37] Y. Yoshida, "The valuation of European options in uncertain environment," European Journal of Operational Research, vol. 145, no. 1, pp. 221-229, 2003.

[38] W.-G. Zhang, Y.-L. Wang, Z.-P. Chen, and Z.-K. Nie, "Possibilistic mean-variance models and efficient frontiers for portfolio selection problem," Information Sciences, vol. 177, no. 13, pp. 2787-2801, 2007.

[39] X. X. Huang, "Mean-entropy models for fuzzy portfolio selection," IEEE Transactions on Fuzzy Systems, vol. 16, no. 4, pp. 1096-1101, 2008.

[40] L. A. Zadeh, "Fuzzy sets," Information and Control, vol. 8, no. 3, pp. 338-353, 1965.

[41] H. Markowitz, "Portfolio selection," The Journal of Finance, vol. 7, no. 1, pp. 77-91, 1952.

[42] X. Zhou, L. Wang, H. Liao, S. Wang, B. Lev, and H. Fujita, “A prospect theory-based group decision approach considering consensus for portfolio selection with hesitant fuzzy information," Knowledge-Based Systems, vol. 168, pp. 28-38, 2019.

[43] Z. Mohamed, D. Mohamad, and O. Samat, "A fuzzy approach to portfolio selection," Sains Malaysiana, vol. 38, no. 6, pp. 895-899, 2009.

[44] Y. Fang, J. Yin, and B. Wu, "Climate change and tourism: a scientometric analysis using Citespace," Journal of Sustainable Tourism, vol. 26, no. 1, pp. 108-126, 2017.
[45] Y.-J. Liu, W.-G. Zhang, and W.-J. Xu, "Fuzzy multi-period portfolio selection optimization models using multiple criteria," Automatica, vol. 48, no. 12, pp. 3042-3053, 2012.

[46] A. Bilbao-Terol, B. Pérez-Gladish, and J. Antomil-lbias, "Selecting the optimum portfolio using fuzzy compromise programming and Sharpe's single-index model," Applied Mathematics and Computation, vol. 182, no. 1, pp. 644-664, 2006.

[47] Á. García-Crespo, J. L. López-Cuadrado, I. González-Carrasco, R. Colomo-Palacios, and B. Ruiz-Mezcua, "SINVLIO: using semantics and fuzzy logic to provide individual investment portfolio recommendations," Knowledge-Based Systems, vol. 27, pp. 103-118, 2012.

[48] P. Gupta, M. K. Mehlawat, and A. Saxena, "A hybrid approach to asset allocation with simultaneous consideration of suitability and optimality," Information Sciences, vol. 180, no. 11, pp. 2264-2285, 2010.

[49] R. Bhattacharyya, P. Kumar, and S. Kar, "Fuzzy R\&D portfolio selection of interdependent projects," Computers \& Mathematics with Applications, vol. 62, no. 10, pp. 3857-3870, 2011.

[50] Z. Qin, X. Li, and X. Ji, "Portfolio selection based on fuzzy cross-entropy," Journal of Computational and Applied Mathematics, vol. 228, no. 1, pp. 139-149, 2009.

[51] X. Huang, Q. Zhang, and Q. Yang, "A review of uncertain portfolio selection," Journal of Intelligent \& Fuzzy Systems, vol. 32, no. 6, pp. 4453-4465, 2017.

[52] T. Hasuike, H. Katagiri, and H. Ishii, "Portfolio selection problems with random fuzzy variable returns," Fuzzy Sets and Systems, vol. 160, no. 18, pp. 2579-2596, 2009.

[53] C. Carlsson and R. Fullér, "Fuzzy sets and fuzzy logic," Fuzzy Reasoning in Decision Making and Optimization, vol. 131, no. 1, pp. 1-2, 2002.

[54] W.-G. Zhang and Z.-K. Nie, "On admissible efficient portfolio selection problem," Applied Mathematics and Computation, vol. 159, no. 2, pp. 357-371, 2004.

[55] J. D. Bermúdez, J. V. Segura, and E. Vercher, "A multi-objective genetic algorithm for cardinality constrained fuzzy portfolio selection," Fuzzy Sets and Systems, vol. 188, no. 1, pp. 16-26, 2012.

[56] P. Gupta, M. Inuiguchi, M. K. Mehlawat, and G. Mittal, "Multiobjective credibilistic portfolio selection model with fuzzy chance-constraints," Information Sciences, vol. 229, pp. 1-17, 2013. 